\title{
Gab2 Ablation Reverses the Stemness of HER2-Overexpressing Breast Cancer Cells
}

\author{
Peng Zhang ${ }^{a} \quad$ Yiying Chen ${ }^{a} \quad$ Miaomiao Gong ${ }^{a} \quad Z^{2}$ humei Zhuanga ${ }^{a}$ Yueyue Wang ${ }^{a}$ \\ Lin $\mathrm{Mu}^{\mathrm{a}}$ Tianjiao Wang ${ }^{\mathrm{a}}$ Jinjin Pan ${ }^{\mathrm{a}}$ Yanan Liu ${ }^{\mathrm{a}}$ Jianming $\mathrm{Xu}^{\mathrm{b}}$ Rui Liang ${ }^{\mathrm{a}}$ \\ Yuhui Yuan ${ }^{\mathrm{a}}$ \\ aDepartment of General Surgery, The Second Affiliated Hospital, Institute of Cancer Stem Cell, Dalian \\ Medical University Cancer Center, Dalian, China, ${ }^{b}$ Department of Molecular and Cellular Biology, Baylor \\ College of Medicine, Houston, USA
}

\section{Key Words}

Breast cancer $• \mathrm{Gab} 2 \cdot \mathrm{HER} 2 \cdot$ Cancer stem cells

\begin{abstract}
Background/Aims: HER2 has been implicated in mammary tumorigenesis as well as aggressive tumor growth and metastasis. Its overexpression is related to a poor prognosis and chemoresistance in breast cancer patients. Although Grb2-associated binding protein 2 (Gab2) is important in the development and progression of human cancer, its effects and mechanisms in HER2-overexpressing breast cancer are unclear. Methods: Clone formation and MTT assays were used to examine cell proliferation. To detect the effect of Gab2 on the stemness of breast cancer cells, we used flow cytometry, a sphere formation assay, realtime PCR, and western blot. An animal model was created to validate the effect of Gab2 on tumor growth in vivo. Tissue slides were analyzed by immunohistochemistry. Results: Knockdown of Gab2 suppressed PI3K/AKT and MAPK/ERK pathway activity. Gab2 ablation also reduced the stemness of HER2-overexpressing breast cancer cells. In vivo, knockdown of Gab2 inhibited tumor growth. Conclusion: This study unveils a potential function of Gab2 in HER2-overexpressing breast cancer cells. Gab2 might be a potential target in the clinical therapy of HER2-overexpressing breast carcinoma.
\end{abstract}

\section{Introduction}

Breast cancer is currently the most common tumor in women. The high rate of breast cancer-related deaths and its high metastasis means that breast cancer is now the most common cause of death in women $[1,2]$. Between $15 \%$ and $23 \%$ of breast cancers show amplification and/or overexpression of the human epidermal growth factor receptor-2 (HER2) gene [3-5]. This receptor is mainly involved in signaling pathways that regulate

P. Zhang and Y. Chen contributed equally to this work.

Yuhui Yuan, MD, PhD

and Rui Liang, MD, PhD
Department of General Surgery, The Second Affiliated Hospital, Institute of Cancer Stem Cell

Dalian Medical University Cancer Center, Dalian (China)

E-Mail yuhuiyuan@hotmail.com; Ir9311038@yahoo.com 
cell proliferation, differentiation, migration, and apoptosis [6-9]. HER2 is a member of the epidermal growth factor receptor (EGFR) family of transmembrane tyrosine kinases. Clinical observations indicate that tumors with high levels of HER2 have poor outcomes [10-12]. HER2 acts as both a prognostic marker and direct therapeutic target [13].

Treatment strategies that combine surgery with adjuvant chemotherapy can improve survival but patients often eventually acquire resistance to chemotherapeutic agents [14, 15]. However, recent studies showed that trastuzumab-conjugated nanoparticles with simultaneous encapsulation of anti-miR-21 and 5-fluorouridine may boost the biological and clinical potential of cancer treatment [16]. Several preclinical and clinical studies suggested that both de novo and acquired resistance to chemotherapeutic agents in breast cancers are associated with elevated levels of HER2 [17-19]. Recently, studies of human breast cancers showed that there is a correlation between HER2 amplification and breast cancer stem cells (BCSCs), also known as cancer stem-like cells or tumor-initiating cells [20-22]. These cells have been linked to tumor growth, metastasis, recurrence, and chemoresistance [14, 22-25].

Grb2-associated binding protein 2 (Gab2) belongs to the Grb-associated binder (Gab) family of scaffolding adapters, which also includes mammalian Gab1 and Gab3, Drosophila DOS, and C. elegans SOC-1 [26]. Gab2 contains a pleckstrin homology domain at the N terminus and proline-rich motifs and multiple tyrosine phosphorylation sites at the $\mathrm{C}$ terminus [26, 27]. Gab2 maps to a chromosomal region (11q13) [28] that is frequently amplified in breast cancer cells [29]. Previous results showed that Gab2 is one of a number of genes predicting lymphoid metastasis in breast cancer [30]. Gab2 is upregulated in numerous human malignancies, such as breast cancer [29, 31, 32], ovarian cancer [33], liver cancer [34, 35], and melanoma [36]. Notably, the Gab2 gene is amplified in approximately $10-15 \%$ of breast cancers [32]. In several cancers, elevated expression of Gab2 is associated with proliferation, metastasis, and invasion [32, 36-38]. However, the effects of Gab2 in HER2-overexpressing breast cancer are not clear.

In our study, knockdown of Gab2 inhibited cell proliferation and xenograft tumor growth. Gab2 depletion suppressed the stemness of HER2-overexpressing breast cancer cells. Thus, we demonstrated that Gab2 plays an important role in regulating stemness. This result may have important implications for breast cancer therapy, and Gab2 may be a new target for HER2-overexpressing breast cancer treatment.

\section{Materials and Methods}

\section{Cell lines and reagents}

T47D-control (T47D-ctl) cells were stably transfected with pCMV4 blank plasmid and T47D-HER2 cells were stably transfected with pCMV-HER2 plasmid. HER2 full-length human cDNA was kindly provided by Dr. Dihua Yu (MD Anderson Cancer Center, Houston, TX). The sequences of the HER2 insert in pCMV4 and the HER2 itself were confirmed by sequencing. T47D-HER2-shGab2 cells were stably transfected with pLKO.1 Gab2 short hairpin RNA (shRNA). Lentiviral-based pLKO.1 Gab2 shRNA was purchased from Origene (Rockville, MD). Stable colonies were selected in the presence of $0.750 \mathrm{mg} / \mathrm{mL}$ zeocin (Invitrogen, Life Technologies, Carlsbad, CA). HCC1954-control (HCC1954-ctl) cells were transfected with negative control small interfering RNA (siRNA), HCC1954-siHER2 cells were transfected with HER2 siRNA, and HCC1954siGab2 cells were transfected with Gab2 siRNA. siRNA and negative control siRNA were purchased from Invitrogen. All cell lines were cultured in RPMI 1640 medium (Gibco, Life Technologies) with 10\% fetal bovine serum (Gibco, Life Technologies), 100 units $/ \mathrm{mL}$ penicillin, and $100 \mu \mathrm{g} / \mathrm{mL}$ streptomycin. The cells were maintained in a humidified atmosphere at $37^{\circ} \mathrm{C}$ and $5 \% \mathrm{CO}_{2}$.

Western blot analysis

Approximately $2 \times 10^{6}$ cells of each cell line were prepared overnight in 6-well plates. After the appropriate treatment, the cells were lysed using RIPA buffer. Protein concentrations were determined by the BSA method (Thermo Fisher Scientific, Waltham, MA). Equal amounts of lysate protein $(25 \mu \mathrm{g})$ were used for sodium dodecyl sulfate-polyacrylamide gel electrophoresis. After gel electrophoresis, the gel was 


\section{Cellular Physiology Cell Physiol Biochem 2018;50:52-65 \begin{tabular}{l|l|l} 
and Biochemistry 10.1159/000493957 & $\begin{array}{l}\text { (c) 2018 The Author(s). Published by S. Karger AG, Basel } \\
\text { www.karger.com/cpb }\end{array}$
\end{tabular} \\ Zhang et al.: Gab2 Ablation Reverses the Stemness Induced by HER2}

transferred to a nitrocellulose membrane (Millipore, Burlington, MA) for $1 \mathrm{~h}$. The membrane was blocked for $2 \mathrm{~h}$ in $5 \%$ skim milk at room temperature, then washed three times with Tris-buffered saline with Tween 20 and incubated overnight with the primary antibody at $4^{\circ} \mathrm{C}$. Anti-HER2, -Gab2, -AKT, -pAKT, -ERK, -pERK, -c-Myc, -KLF4, -Oct4, -Sox2, and -GAPDH rabbit antibodies were purchased from Cell Signaling Technology (Danvers, MA). Anti-ALDH1 mouse antibody was purchased from BD Biosciences (Franklin Lakes, NJ). Anti-CD133 rabbit antibody was purchased from Proteintech (Chicago, IL). Next, the membranes were incubated for 1 hour at room temperature with the appropriate secondary antibodies and detected by chemiluminescence.

\section{Real-time quantitative reverse transcription PCR}

Cells from each experimental group were collected by centrifugation. Total RNA was isolated by using Trizol (Takara, Dalian, China) according to the manufacturer's protocol. One microgram RNA was reverse transcribed into single-stranded cDNA using the PrimeScript RT Reagent Kit (Takara). Quantitative real-time reverse transcription PCR (qRT-PCR) was performed in a 7500 fast real-time PCR amplifier (QX200, Biorad, USA) using SYBR Green PCR Master Mix (Takara). PCR primers are shown in Table 1. The PCR cycling conditions were as follows: initial denaturing at $94^{\circ} \mathrm{C}$ for $30 \mathrm{~s}$ followed by 40 cycles of denaturing at $94^{\circ} \mathrm{C}$ for $5 \mathrm{~s}$, annealing at $56^{\circ} \mathrm{C}$ for $30 \mathrm{~s}$, and elongation at $72^{\circ} \mathrm{C}$ for $20 \mathrm{~s}$. Relative levels were determined using the $2^{-\Delta \Delta \mathrm{Ct}}$ method and $\beta$-actin was used as the internal control. Each sample was run in duplicate and the results are representative of at least three independent experiments.

\section{SiRNA transfection}

The HER2 and Gab2 siRNA and negative control siRNA were purchased from Invitrogen. The transfection was performed by using Lipofectamine 2000 (Invitrogen, Life Technology) reagent following the manufacturer's instructions. HER2 or Gab2 expression was determined by western blot assay after 48$72 \mathrm{~h}$ of HER2 and Gab2 siRNA transfection.

\section{Colony formation assay}

T47D-ctl, T47D-HER2, T47D-HER2-shGab2, HCC1954-ctl, and HCC1954-siGab2 cells were plated at a low density ( $5 \times 10^{2}$ cells per well) in a 6-well plate and incubated for 10 days at $37^{\circ} \mathrm{C}$ and $5 \% \mathrm{CO}_{2}$ in a humidified atmosphere. Colonies were then fixed with $2 \%$ paraformaldehyde, stained with a $0.05 \%$ crystal violet solution (Sigma-Aldrich, St. Louis, MO), and counted under an inverted microscope.

\section{Sphere formation assay}

Cell lines were suspended in an appropriate amount of sphere-forming medium containing serum-free Dulbecco's modified Eagle's medium/F-12 (Gibco, Life Technology), B27 (Invitrogen, Life Technology), 20 $\mathrm{ng} / \mathrm{mL}$ epidermal growth factor (EGF; Sigma-Aldrich), and $20 \mathrm{ng} / \mathrm{mL}$ basic fibroblast growth factor (bFGF; BD Biosciences). Single cells were plated in ultralow attachment 96-well plates at a low density of 500 viable cells per well. T47D-ctl, T47D-HER2, T47D-HER2-shGab2, HCC1954-ctl, and HCC1954-siGab2 cells $\left(5 \times 10^{2}\right.$ per well) were plated in ultralow attachment 96 -well plates. Cells were incubated at $37^{\circ} \mathrm{C}, 95 \%$ humidity, and $5 \% \mathrm{CO}_{2}$ for 7-14 days. Images were taken and sphere-forming efficiency was evaluated on day 7. Spheres were photographed at $100 \times$ magnification.
Table 1. Primers used for qRT-PCR

\begin{tabular}{|c|c|c|}
\hline mRNA & & Sequence \\
\hline \multirow{2}{*}{ HER2 } & Sense & 5'AGCACTGGGGAGT CTTTGTG-3' \\
\hline & Antisense & 5'-CTGAA TGGGTCGCTTTTGTT-3' \\
\hline \multirow{2}{*}{ Gab2 } & Sense & 5'- ACAGTACCTACGAC СТCCCC-3' \\
\hline & Antisense & 5'- CTGGGCGTCTTGAAGGTGTA-3' \\
\hline \multirow{2}{*}{ Oct4 } & Sense & 5'- CAGTGCCCGAA ACCCACAC-3' \\
\hline & Antisense & 5'- GGAGACCCAGCAGCCTCAAA-3' \\
\hline \multirow{2}{*}{ Sox2 } & Sense & 5'- CCCTGTGGTTACCTCTTCC-3' \\
\hline & Antisense & 5'- СТCССАTTTCCСТCGTTT-3' \\
\hline \multirow{2}{*}{ c-Myc } & Sense & 5'- GGAGGCTATTCTGCCCATTTG-3' \\
\hline & Antisense & 5'-CGAGGTCATAGTTCCTGTTGGTG-3' \\
\hline \multirow{2}{*}{ KLF4 } & Sense & 5'- ACCAGGCACTACCGTAAACACA-3' \\
\hline & Antisense & 5'- GGTCCGACCTGGAAAATGCT-3' \\
\hline \multirow{2}{*}{$\beta$-actin } & Sense & 5'-ACTGGAACGGTGAAGGTGACAG-3' \\
\hline & Anticense & 5'-GGTGGCTTTTAGCATGGCAAG-3' \\
\hline
\end{tabular}




\section{Cellular Physiology Cell Physiol Biochem 2018;50:52-65

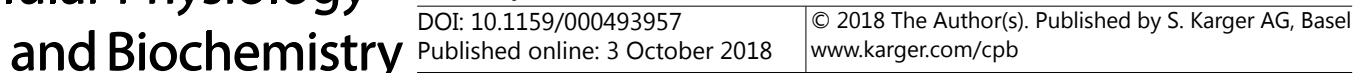

Zhang et al.: Gab2 Ablation Reverses the Stemness Induced by HER2

\section{Flow cytometry analysis}

For flow cytometry analysis, breast cancer cells in the logarithmic growth phase were digested with $0.25 \%$ trypsin and washed three times with phosphate-buffered saline (PBS), followed by re-suspension in $100 \mu \mathrm{L}$ PBS and staining with anti-CD44-PE (BD Biosciences) and anti-CD24-FITC (eBioscience, San Diego, CA) or with their isotype controls at $4^{\circ} \mathrm{C}$ for $30 \mathrm{~min}$ (with agitation every $5 \mathrm{~min}$ ). The samples were then washed three times with PBS and finally re-suspended in $500 \mu \mathrm{L}$ PBS. Flow cytometry analysis was performed on an Accuri ${ }^{\mathrm{TM}}$ C6 Flow Cytometer (Genetimes Technology, Shanghai, China). The expression ratio of CD44 $4^{+}$and CD24- (CD44 /CD24) in different breast cancer cell lines was calculated from the percentage of $\mathrm{CD} 44^{+}$and $\mathrm{CD} 24$ subpopulations in the flow cytometry analysis.

\section{Cell proliferation assay}

Cell proliferation was measured by an MTT assay. T47D-ctl, T47D-HER2, T47D-HER2-shGab2, HCC1954-ctl, and HCC1954-siGAB2 cells $\left(1 \times 10^{4}\right.$ cells per well) were seeded in a 96-well plate in $100 \mu \mathrm{L}$ volumes and incubated overnight at $37^{\circ} \mathrm{C}$ with $5 \% \mathrm{CO}_{2}$. The cells were treated with a series of concentrations of TAM and incubated for $24 \mathrm{~h}$. They were then treated with $10 \mu \mathrm{L}$ of MTT $(0.5 \mathrm{mg} / \mathrm{mL})$ (Sigma-Aldrich) alone and incubated for $4 \mathrm{~h}$ at $37^{\circ} \mathrm{C}$ in a $5 \% \mathrm{CO}_{2}$ incubator. After the medium was removed, $150 \mu \mathrm{L}$ DMSO (Sigma-Aldrich) was added into each well to dissolve the formazan crystal. The absorbance was measured at $490 \mathrm{~nm}$ with a microplate reader.

To plot the cell growth curve, T47D-ctl, T47D-HER2, and T47D-HER2-shGab2 cells were seeded in 96well plates $\left(3 \times 10^{3}\right.$ cells per well). After transfection, an MTT assay was performed to detect cell survival at 1, 2, 3, 4, 5, 6, and 7 days and the optical density was measured at $490 \mathrm{~nm}$. HCC1954-ctl and HCC1954siGab2 cells were seeded in 96-well plates $\left(5 \times 10^{3}\right.$ cells per well). After transfection, an MTT assay was performed to detect cell survival at $24,48,72$, and $96 \mathrm{~h}$ and optical density was measured at $490 \mathrm{~nm}$.

\section{Tumor growth in xenografts}

We used 4-week-old ovariectomized female nude mice to generate an experimental orthotopic breast cancer model. Mice were randomly divided into three groups (five mice per group). T47D-ctl, T47D-HER2, and T47D-HER2-shGab2 cells $\left(1 \times 10^{7}\right)$ suspended in $100 \mu \mathrm{L}$ of 50\% Matrigel (BD Biosciences) were injected into the second left mammary fat pad by subcutaneous injection at the base of the nipple. The mice were treated with estrogen once a week. After the tumor volume reached about $100 \mathrm{~mm}^{3}$, the tumor volumes (A $\times \mathrm{B}^{2} / 2$; $\mathrm{A}$ being the greatest diameter and $\mathrm{B}$ being the diameter perpendicular to $\mathrm{A}$ ) were measured twice $\mathrm{a}$ week by digital calipers. We began to measure the volumes at day 14 after the cell injection. At day 38 , the mice were sacrificed and the tumor xenografts were immediately dissected, weighed, stored, and fixed. All animal procedures were carried out in accordance with the National Institute of Health Guide for the Care and Use of Laboratory Animals under the approval of the Specific Pathogen-Free Laboratory Animal Center at Dalian Medical University.

\section{Immunohistochemistry}

Tumors were fixed in 4\% paraformaldehyde (Sigma-Aldrich) and prepared for histological analysis. Tissue sections were deparaffinized and rehydrated before antigen retrieval and incubation with $1 \% \mathrm{H}_{2} \mathrm{O}_{2}$ in methanol for $15 \mathrm{~min}$ at room temperature to quench endogenous peroxidase. After being blocked with $5 \%$ bovine serum albumin, sections were incubated overnight at $4^{\circ} \mathrm{C}$ with anti-HER2 rabbit monoclonal antibody (1:800 dilution), anti-Sox2 rabbit monoclonal antibody (1:200 dilution) (Cell Signaling Technology), antiGab2 rabbit monoclonal antibody (1:100 dilution), anti-Ki67 rabbit monoclonal antibody (1:500 dilution) (Abcam, Cambridge, MA), and anti-CD133 rabbit monoclonal antibody (1:200 dilution) (Proteintech). Then, a biotinylated anti-mouse or rabbit IgG antibody and an avidin-biotinylated peroxidase complex were applied with 3, 3-diaminobenzidine as a peroxidase substrate to visualize immunoreactivity. A light hematoxylin counterstain was subsequently applied.

\section{Statistical analysis}

All statistical analyses were carried out using SPSS 16.0 software (SPSS Inc., Chicago, IL). Variance analyses and square tests were used for the statistical analysis. Quantitative data are presented as the mean \pm standard deviation and were analyzed using a two-sided Student's $t$ test; for the statistical evaluation of more than two groups, the ANOVA test was used. ${ }^{*} \mathrm{P}<0.05,{ }^{* *} \mathrm{P}<0.01$, ${ }^{* * *} \mathrm{P}<0.001$. 


\section{Results}

Expression of Gab2 is increased in HER2-overexpressing breast cancer cells

To determine whether Gab2 was upregulated with HER2 overexpression, we compared the mRNA and protein levels of HER2 and Gab2 in T47D-ctl and T47D-HER2 (HER2overexpressing) cells. qRT-PCR results showed that, with an elevated HER2 mRNA level (Fig. 1a), the expression of Gab2 mRNA was much higher in T47D-HER2 cells than in T47D-ctl cells (Fig. 1b). Western blot results indicated that Gab2 protein was also significantly increased in T47D-HER2 cells compared with T47D-ctl cells. In contrast, when we knocked down HER2 in T47D-HER2 cells using HER2-siRNA, the expression of Gab2 was reduced (Fig. 1c). We also examined the protein expression of HER2 and Gab2 in xenografts by immunohistochemistry analysis. As shown in Fig. 1d, the protein expression of HER2 and Gab2 in the group injected with T47D-HER2 cells was much higher compared with the group injected with T47D-ctl cells.

Knockdown of Gab2 decreases the activity of HER2 downstream pathways and reduces cell proliferation

To clarify the role of Gab2 in HER2-overexpressing cells, we analyzed the activation of HER2 downstream pathways and the viability of cell proliferation using T47D-ctl, T47DHER2, and T47D-HER2-shGab2 cell lines. Western blot results suggested that the levels of pERK and pAKT in HER2-overexpressing cells (T47D-HER2 cells) were much higher than in T47D-ctl cells, whereas when we knocked down Gab2 in T47D-HER2 cells, the levels of pERK and pAKT were reduced (Fig. 2a). A colony formation assay showed that the colony numbers of T47D-HER2-shGab2 cells were significantly decreased compared with T47D-HER2 cells (Fig. 2b). A cell growth curve showed that the proliferation of T47D-HER2-shGab2 cells was also suppressed compared with T47D-HER2 cells (Fig. 2c).

Fig. 1. Expression of Gab2 is increased in HER2-overexpressing breast cancer cells. (a) qRT-PCR analysis of the HER2 mRNA level in T47D-ctl and T47D-HER2 cell lines. (b) qRT-PCR analysis of the Gab2 mRNA level in T47D-ctl and T47D-HER2 cell lines. In all graphs, the expression levels of $\beta$-actin were used as the normalized control. (c) T47D-ctl and T47D-HER2 cells (both transfected with negative control siRNA) and T47D-HER2 cells (transfected with HER2-siRNA) were subjected to western blot analysis to determine the protein expression of HER2, Gab2, and GAPDH. (d) Tissue slides were analyzed by immunohistochemistry using anti-HER2 and anti-Gab2 antibodies.

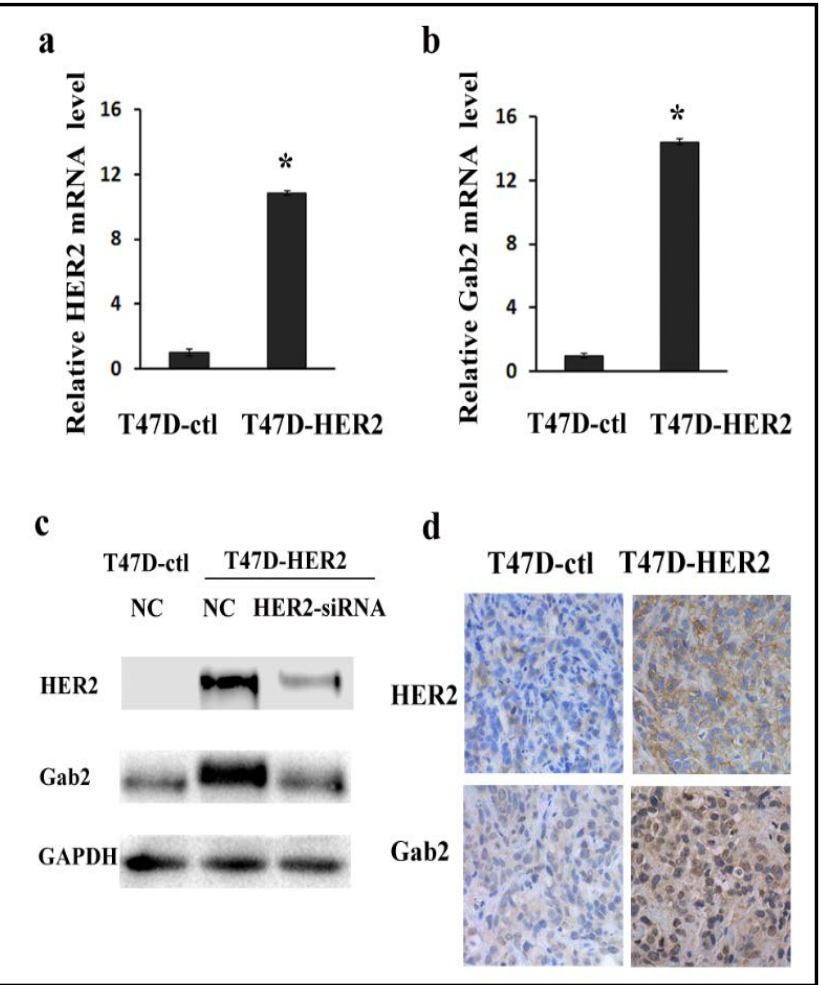


Fig. 2. Knockdown of Gab2 decreases the activity of HER2 downstream pathways and cell proliferation. (a) T47D-ctl, T47DHER2, and T47D-HER2-shGab2 cells were subjected to western blot analysis to determine the protein expression of HER2, Gab2, pAKT, AKT, pERK, ERK, and GAPDH. (b) A clone formation assay was performed to analyze the proliferation of T47D-ctl, T47D-HER2, and T47D-HER2shGab2 cells. (c) Cell proliferation was examined by an MTT assay in T47D-ctl, T47D-HER2, and T47DHER2-shGab2 cells.

Fig. 3. Gab2 ablation reduces sphere formation in HER2-overexpressing breast cancer cells. (a) Breast cancer cell mammospheres cultured in medium were photographed; representative images are shown. Ten-day-old T47D-ctl, T47DHER2, and T47D-HER2-shGab2 cell spheres cultured in medium were photographed; representative images are shown. (b) and (c) The numbers and diameters of the spheres were measured as described in the Materials and Methods. The values from three independent experiments are presented in the bar graph.
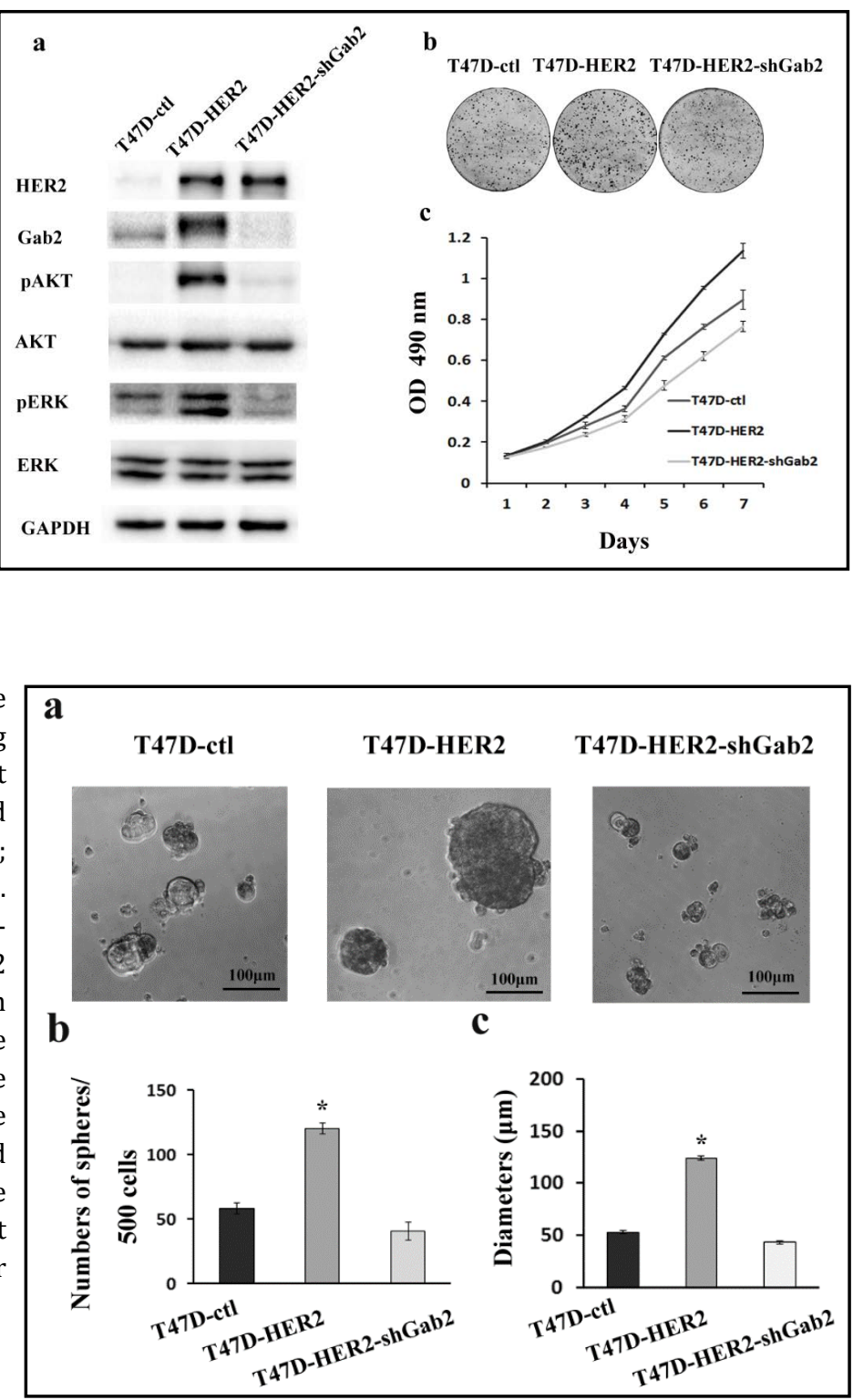

Gab2 ablation reduces sphere formation in HER2-overexpressing breast cancer cells

Cancer stem cells can be expanded as sphere-like cellular aggregates in sphere medium containing EGF and bFGF. To further determine the role of Gab2 in the stem cell-like phenotype by using T47D-ctl, T47D-HER2 and T47D-HER2-shGab2 cells, a sphere formation assay was performed. The results showed that the sphere formation viability of T47D-HER2 cells was much higher than that of T47D-ctl cells. However, knockdown of Gab2 in T47D-HER2 cells resulted in significantly lower sphere formation numbers (Fig. 3a). The sphere numbers and diameters were also measured. As shown in Fig. $3 \mathrm{~b}$ and c, the sphere sizes were smaller with knockdown of Gab2 in T47D-HER2 cells compared with T47D-HER2 cells. The numbers of spheres in T47D-HER2-shGab2 cells were also reduced compared with T47D-HER2 cells.

Downregulation of Gab2 suppresses self-renewal gene expression and reduces $C D 44^{+}$/ CD24- populations in HER2-overexpressing breast cancer cells

Previous results showed that c-Myc, KLF4, Oct4, and Sox2 are the key stem cell transcription factors (SCTFs) [24]. These self-renewal genes were analyzed by qRT-PCR. As shown in Fig. 4a, the mRNA levels of these SCTFs in T47D-HER2 cells were upregulated 
compared with T47D-ctl cells. The mRNA levels of SCTFs were decreased with knockdown of Gab2. In addition, we evaluated the protein expression of these SCTFs. As shown in Fig. $4 \mathrm{~b}, \mathrm{Gab} 2$ also suppressed the protein expression of the self-renewal genes, including c-Myc, KLF4, Oct4, and Sox2, compared with T47D-HER2 cells. Furthermore, flow cytometric analysis (Fig. 5) demonstrated that the $\mathrm{CD} 44^{+} / \mathrm{CD} 24^{-}$populations were higher in T47DHER2 cells and that knockdown of Gab2 in T47D-HER2 cells resulted in significantly lower ratios of $\mathrm{CD} 44^{+} / \mathrm{CD} 24^{-}$.

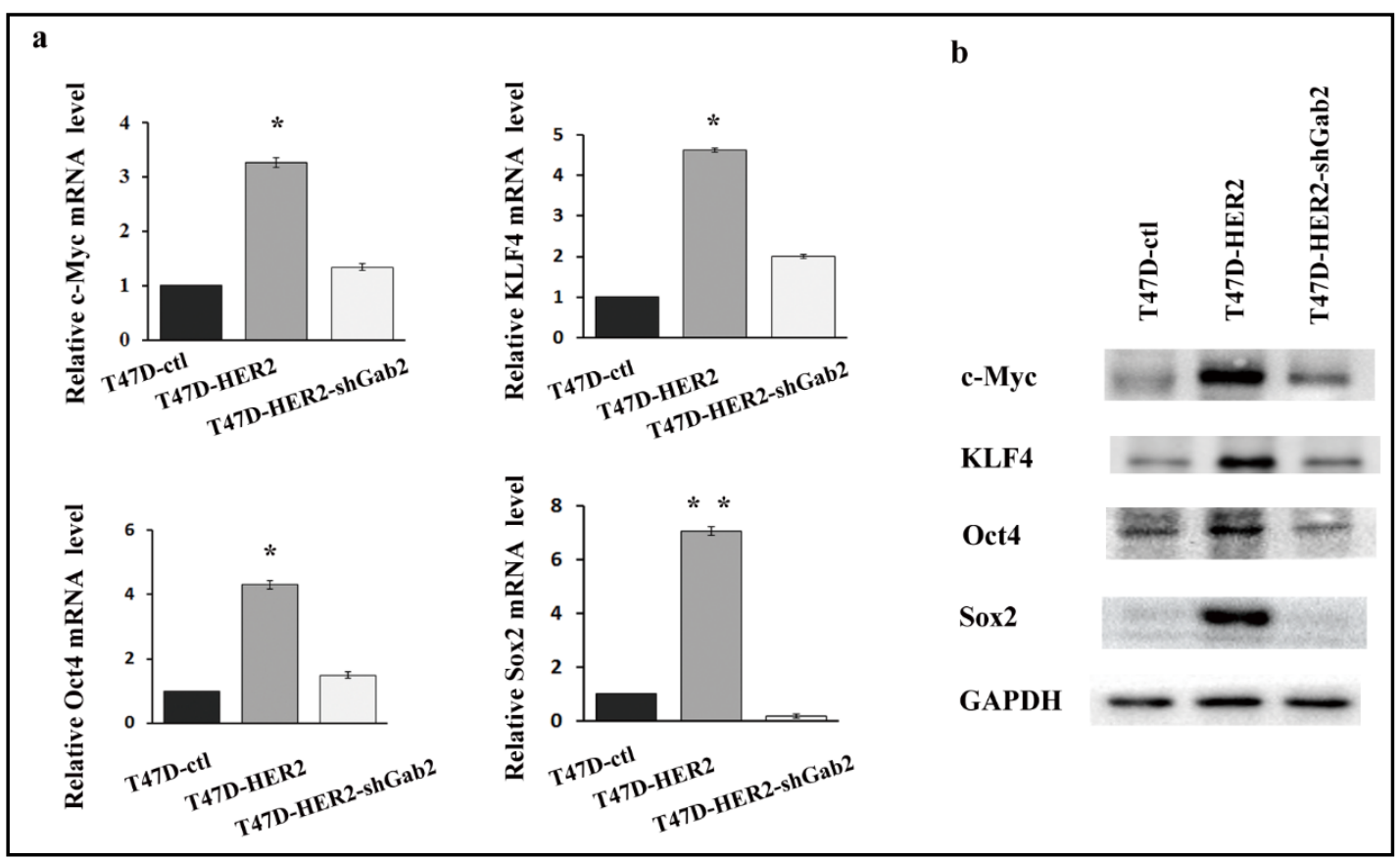

Fig. 4. Downregulation of Gab2 suppresses self-renewal gene expression in HER2-overepressing breast cancer cells. (a) qRT-PCR analysis of c-Myc, KLF4, Oct4, and Sox2 for breast cancer cells with high or low levels of HER2 and Gab2. In all graphs, the expression levels of $\beta$-actin were used as a normalized control. (b) T47D-ctl, T47D-HER2, and T47D-HER2-shGab2 cells were subjected to western blot analysis to determine the expression of c-Myc, KLF4, Oct4, Sox2, and GAPDH.

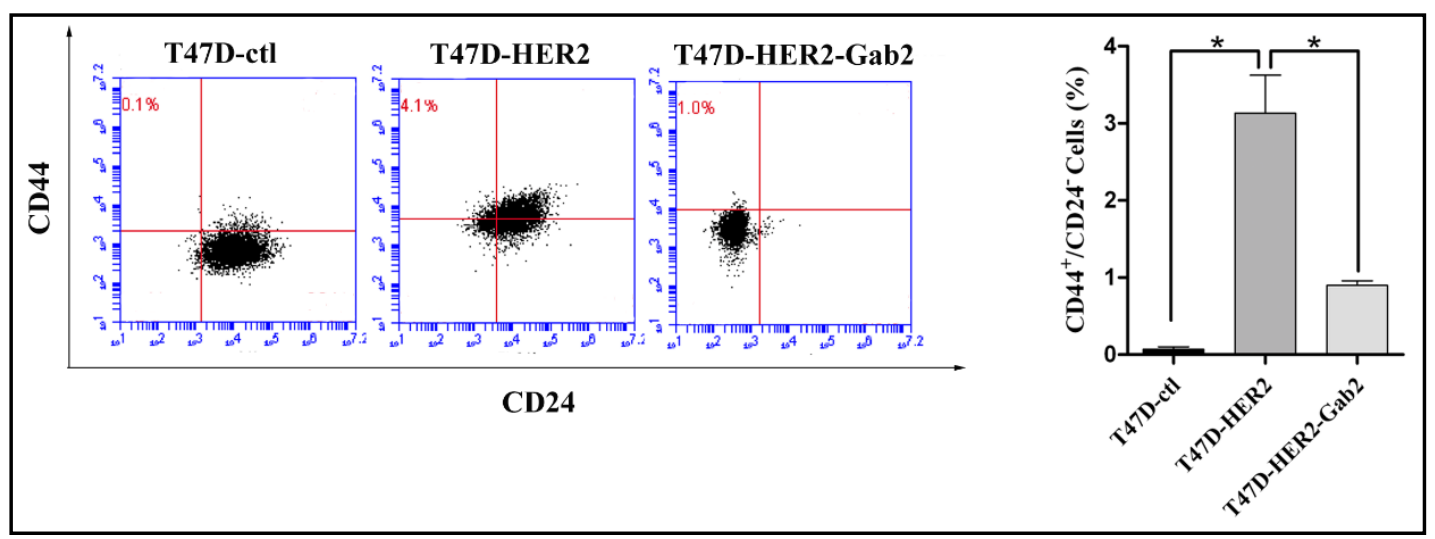

Fig. 5. Gab2 governs the stemness of HER2-overepressing breast cancer cells. Our study used CD44 and CD24 expression as stem cell markers. Cancer cells expressing low CD24 and high CD44 were recognized as the stem cell population. Knockdown of Gab2 reduced CD44 ${ }^{+} / \mathrm{CD} 24^{-}$populations. Differences between the two groups were analyzed using t tests. $\mathrm{n}=3 ;^{*}, \mathrm{P}<0.05$. 
Fig. 6. Gab2 plays an i m portant role in human HER2p o s i t i v e breast cancer cell lines. (a) MCF-7, T47D, and HCC1954 cells were subjected to western blot analysis to determine the protein expression of HER2, Gab2, and GAPDH. (b) HCC1954ctl cells (transfected with negative c o n t r o l siRNA) and H C C 1954 siHER2 cells (transfected with HER2siRNA) were subjected to western blot analysis to determine the protein expression of HER2, Gab2, and GAPDH. (c) A clone formation assay was performed to analyze the a

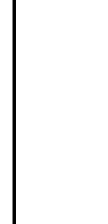

c

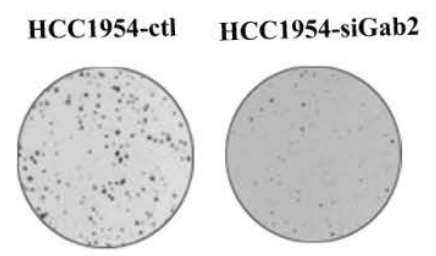

d

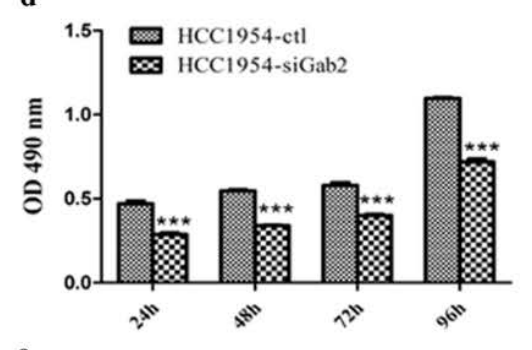

f

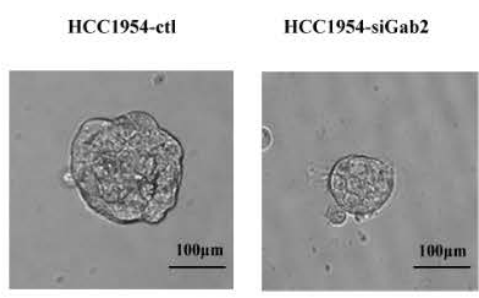

g

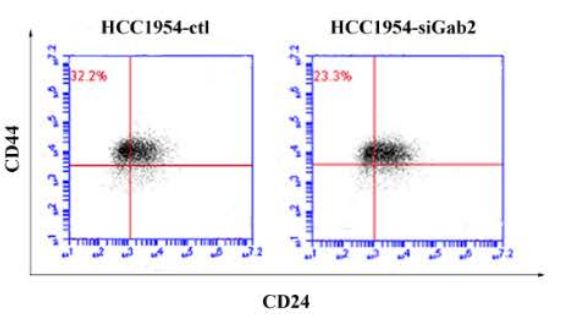

b

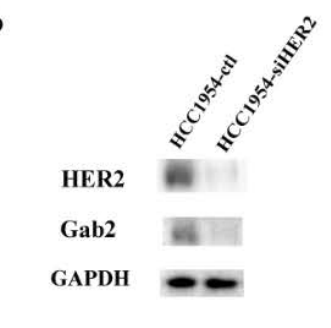

e

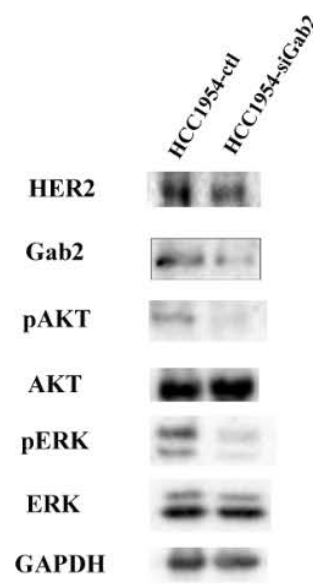

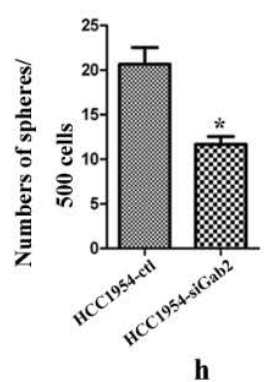

h
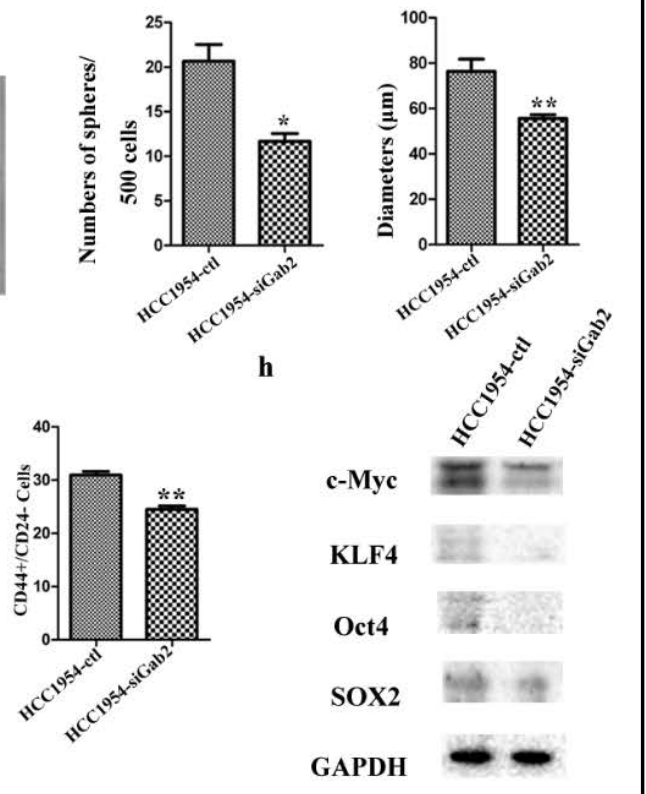

proliferation

of HCC1954-ctl and HCC1954-siGab2 cells. (d) Cell proliferation was examined by an MTT assay in HCC1954ctl and HCC1954-siGab2 cells. (e) HCC1954-ctl and HCC1954-siGab2 cells were subjected to western blot analysis to determine the protein expression of HER2, Gab2, pAKT, AKT, pERK, ERK, and GAPDH. (f) Representative sphere formation results of HCC1954-ctl and HCC1954-siGab2 cells. The numbers and diameters of the spheres were measured as described in the Materials and Methods. (g) Flow cytometry analysis showed that HCC1954-siGab2 cells exhibited a lower fraction of CD44+/CD24- cells. (h) HCC1954ctl and HCC1954-siGab2 cells were subjected to western blot analysis to determine the expression of c-Myc, KLF4, Oct4, Sox2, and GAPDH. 
Gab2 plays an important role in human HER2-positive breast cancer cell lines

To directly study the role of Gab2 in human HER2-positive (HER2+) breast cancer cell lines, we first profiled Gab2 expression in MCF-7, T47D, and HCC1954 (HER2 ${ }^{+}$) cell lines (Fig. 6a). We observed higher Gab2 levels in the HCC1954 cell line. As expected, knockdown of HER2 reduced the expression of Gab2 in HCC1954 cells (Fig. 6b). To test whether Gab2 can drive the growth of HER2 ${ }^{+}$breast cancer, Gab2 siRNA was used to knockdown Gab2 expression (Fig. 6e). Clone formation (Fig. 6c) and MTT (Fig. 6d) assays revealed that the proliferation of HCC1954-siGab2 cells was suppressed compared with HCC1954-ctl cells. Additionally, when we knocked down Gab2 in HCC1954 cells, the levels of pERK and pAKT were also reduced (Fig. 6e). To further confirm the role of Gab2 in stem-like cells of HCC1954, a sphere formation assay was used to reveal the function of Gab2. Compared with HCC1954ctl cells, the sphere sizes and numbers were all decreased in HCC1954-siGab2 cells (Fig. 6f). Next, we tested the effect of Gab2 on the expression levels of CD44 and CD24 in HCC1954-ctl and HCC1954-siGab2 cells. The CD44 ${ }^{+}$CD24- fraction was decreased (Fig. 6g). Gab2 also suppressed the protein expression of the self-renewal genes, including c-Myc, KLF4, Oct4, and Sox2, compared with HCC1954-siGab2 cells (Fig. 6h).

Knockdown of Gab2 significantly reduces xenograft tumor growth and the expression of self-renewal genes in vivo

The effect of Gab2 on tumor growth was further examined in nude mice with human breast tumor xenografts. T47D-ctl, T47D-HER2, and T47D-HER2-shGab2 cells were injected into the mice. As shown in Fig. 7a, a tumor growth chart revealed that the tumor volumes increased rapidly when the mice were injected with T47D-HER2 cells. Knockdown of Gab2 in T47D-HER2 cells significantly inhibited the growth of xenograft tumors. When we extracted the tumors from the mice, the results showed that the tumor volume in mice injected with T47D-HER2shGab2 cells was much smaller compared with the group injected with T47D-HER2 cells (Fig. 7b). Furthermore, the expression of self-renewal genes in xenografts was analyzed by western blot and immunohistochemistry. As shown in Fig. 8a, for the Gab2 ablation group, the protein expression of self-renewal genes was decreased compared with the T47D-HER2 cell group. Immunohistochemistry showed that the expression levels of Ki67, Sox2, and CD133 in tumors extracted from the nude mice injected with T47D-HER2-shGab2 cells were much lower compared with tumors injected with T47DHER2 cells (Fig. 8b).

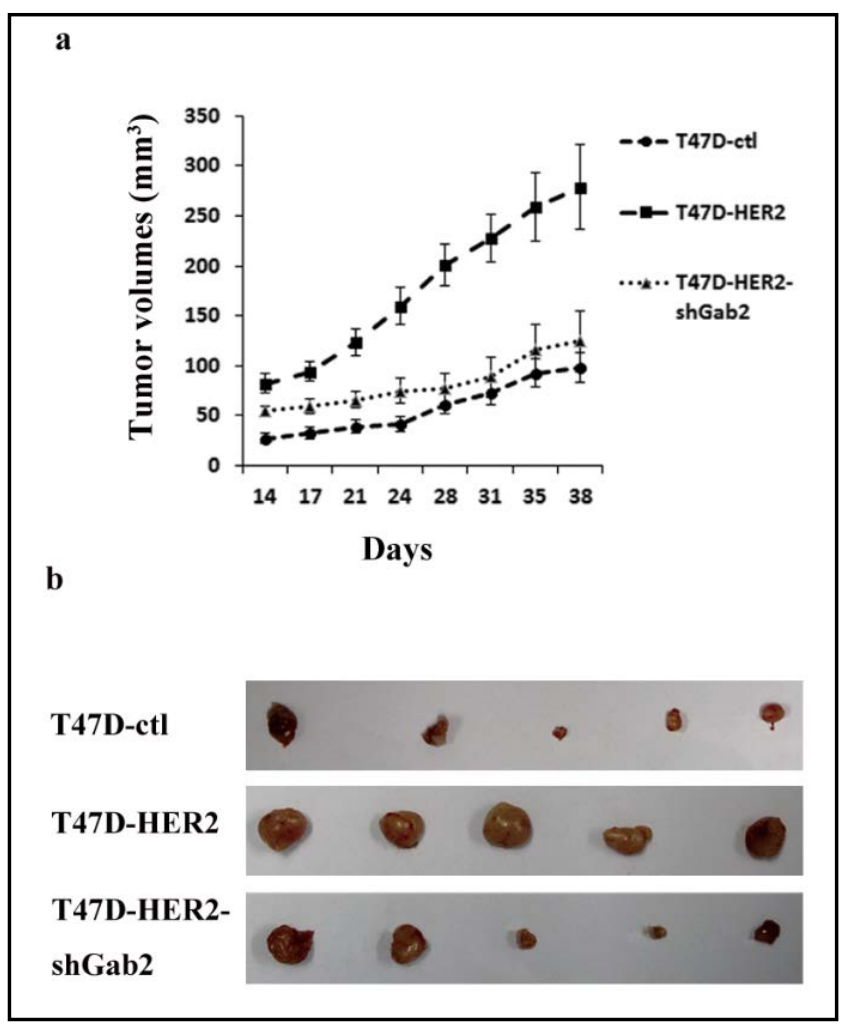

Fig. 7. Knockdown of Gab2 significantly reduces xenograft tumor growth. (a) The tumor volume of each group of nude mice was measured and calculated as $V=\left(\right.$ width $^{2} \times$ length $) / 2$. $\mathrm{n}=5$; * $\mathrm{P}<0.05$. (b) Representative photographs of tumors extracted from mice injected with T47D-ctl, T47D-HER2, and T47D-HER2-shGab2 cells. 


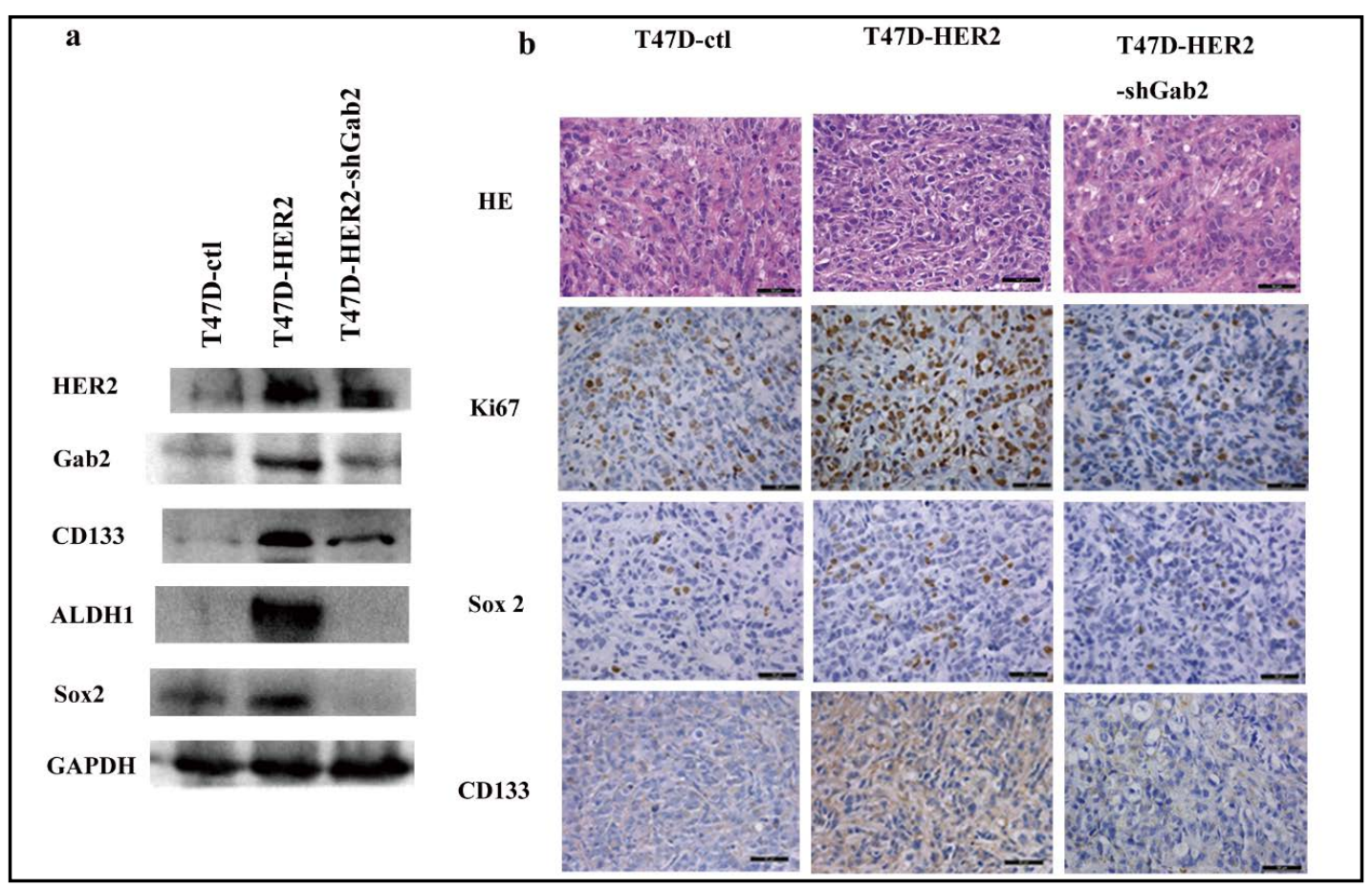

Fig. 8. Knockdown of Gab2 significantly reduces the expression of self-renewal genes in vivo. (a) The proteins were extracted from tumor xenografts. HER2, Gab2, CD133, ALDH1, and Sox2 expressions were detected by western blot. (b) Tissue slides were analyzed by immunohistochemistry using anti-Ki67, antiSox2, and anti-CD133 antibodies.

\section{Discussion}

Gab2 has been proposed to be a critical regulator of human cancer development and progression. High levels of Gab2 expression have been detected in breast cancer cell lines and primary tumors [32, 39]. Our results also revealed that when the HER2 oncogene was overexpressed or present in T47D and HCC1954 cells, the expression of Gab2 was upregulated. Conversely, knockdown of HER2 by siRNA had the opposite effect (Fig. 1a-c, Fig. $6 a$ and b). Gab2 expression was also upregulated in xenograft tumors injected with HER2overexpressing cells (Fig. 1d). Previous work showed that overexpression of Gab2 in MCF$10 \mathrm{~A}$ cells increases cell proliferation and alters growth factor dependency [37]. In addition, other results showed that Gab2 promotes the proliferation of mammary cells cooperating with HER2 [40]. Elevated expression of Gab2 has been found in breast tumors induced by HER2 in mice [41]. In transgenic mice, Gab2 is required for efficient HER2-driven mammary tumorigenesis and metastatic spread [32, 41], and overexpression of Gab2 accelerates HER2-induced mammary tumorigenesis [32]. Gab2 and HER2 are co-amplified in a subset of breast carcinomas, and co-expression of Gab2 with HER2 results in an invasive phenotype and increases the proliferation of MCF-10A mammary cells in a three-dimensional culture system [32]. Our data indicated that cell proliferation was increased in HER2-overexpressing cells (T47D-HER2 cells) and that knockdown of Gab2 in T47D-HER2 cells decreased their cell proliferation (Fig. 2b-c). Moreover, the proliferation of HCC1954-siGab2 cells was also suppressed compared with HCC1954-ctl cells (Fig. 6c-d). However, the mechanism underlying the elevated expression of Gab2 in HER2-overexpressing breast cancer cells is still unclear. Further research would be valuable to explore the mechanism in detail.

Scaffolding adapter proteins may play critical roles in coupling/amplifying signals emanating from growth factor receptors [41]. Gab2 appears to have marked effects on the activity of the PI3K/AKT and MAPK/ERK pathways [42]. Higher levels of Gab2 promote 
melanoma growth and metastasis in vivo by activating PI3K/AKT signaling [43]. In addition, Gab2 enhances the activity of the PI3K/AKT and MAPK/ERK pathways in ovarian cancer cells [33]. Moreover, Gab2 silencing impairs the growth and migration of H1975 cells by modulating PI3K/AKT signaling in non-small cell lung cancer [44]. Our results indicated that knockdown of Gab2 suppressed the activity of both PI3K/AKT and MAPK/ERK pathways in HER2-overexpressing breast cancer cells (Fig. 2a and Fig. 7e).

The theory of cancer stem cells, which are also known as cancer stem-like cells or tumor-initiating cells, posits that several cancers, including breast cancer, are hierarchically organized and driven by a population of cells that display stem cell properties [45-47]. BCSCs, which constitute a small subset of cells in human breast cancers, promote the tumorigenic and metastatic properties of some breast cancers, and a subpopulation of cells expressing the $\mathrm{CD} 44^{+} / \mathrm{CD} 24^{-}$phenotype has been reported to represent such stem-like populations [20, 48]. Moreover, the CD44 $/ \mathrm{CD} 24^{-}$breast cancer cell population is enriched in tumor-initiating and chemotherapy-resistant cells. These cells highly express genes involved in invasion and angiogenesis and display activated TGF- $\beta$, Hh, and PLAU signaling pathways. The prevalence of $\mathrm{CD} 44^{+} / \mathrm{CD} 24^{-}$cells in breast cancer patients indicates a link between high numbers of stem-like cancer cells and metastasis $[49,50]$. Recently, several studies indicated that HER2 is an important regulator of the BCSC population in HER2-overexpressing breast cancers $[51,52]$. Our results showed that the expression of BCSC-related proteins was upregulated in T47D-HER2 cells compared with control cells. Previous studies also suggested that HER2 overexpression drives mammary carcinogenesis, tumor growth, and invasion through its effects on BCSCs [21]. HER2-overexpressing BCSCs are causally associated with an aggressive phenotype and radiotherapy resistance [19]. HER2 regulates BCSCs through several signaling pathways, such as the PI3K/AKT, Wnt [21, 53], and MAPK/ERK pathways [54, 55]. In HER2positive breast cancers, HER2 interacts with CXCR1, which is selectively expressed in BCSCs [56]. These pathways provide potential targets for therapeutic intervention. Our results showed that knockdown of Gab2 reduced the mRNA and protein expression of self-renewal genes both in vitro and in vivo. Furthermore, the sphere formation ability and percentage of $\mathrm{CD} 44^{+} / \mathrm{CD} 24^{-}$cells were reduced with Gab2 ablation. Downregulation of Gab2 suppresses tumor growth in xenograft tumor models (Figs. 3-8).

From the above, we conjecture that the effects of Gab2 on stemness may at least partially be due to suppression of the PI3K/AKT and MAPK/ERK pathways, which are downstream of HER2-induced pathways. Further research is required to explore the mechanism in detail.

\section{Conclusion}

This study unveiled a potential function of Gab2 in regulating the stemness of HER2overexpressing breast cancer cells. Knockdown of Gab2 suppressed mammosphere formation. Gab2 ablation also reduced the expression of self-renewal genes and proteins in vitro and in a xenograft mouse model. These findings indicated that Gab2 might be a potential target in the clinical therapy of HER2-overexpressing breast carcinoma.

\section{Abbreviations}

BCSC (breast cancer stem cell); bFGF (basic fibroblast growth factor); EGF (epidermal growth factor); EGFR (epidermal growth factor receptor); Gab2 (Grb2-associated binding protein 2; HER2 (human epidermal growth factor receptor-2); PBS (phosphate-buffered saline); qRT-PCR (quantitative real-time reverse transcription polymerase chain reaction); SCTF (stem cell transcription factor); shRNA (short hairpin RNA); siRNA (small interfering RNA). 


\section{Cellular Physiology Cell Physiol Biochem 2018;50:52-65 \begin{tabular}{l|l} 
and Biochemistry Published online:3 October 2018 & $\begin{array}{l}\text { (c) } 2018 \text { The Author(s). Published by S. Karger AG, Basel } \\
\text { www.karger.com/cpb }\end{array}$
\end{tabular}}

Zhang et al.: Gab2 Ablation Reverses the Stemness Induced by HER2

\section{Acknowledgements}

This work was supported by funding from the National Natural Science Foundation of China (No. 81472492) to Yuhui Yuan. The funder had no role in the study design, data collection and analysis, decision to publish, or preparation of the manuscript.

\section{Disclosure Statement}

The authors declare to have no competing interests.

\section{References}

1 Szalayova G, James TA, Rincon M: A framework for the role of acute inflammation in tumor progression. Breast Cancer Res Treat 2015;151:235-238.

- Pan Z, Jing W, He K, Zhang L, Long X: Satb1 is correlated with progression and metastasis of breast cancers: A meta-analysis. Cell Physiol Biochem 2016;38:1975-1983.

-3 Kumler I, Tuxen MK, Nielsen DL: A systematic review of dual targeting in her2-positive breast cancer. Cancer Treat Rev 2014;40:259-270.

-4 Ballinger TJ, Sanders ME, Abramson VG: Current her2 testing recommendations and clinical relevance as a predictor of response to targeted therapy. Clin Breast Cancer 2015;15:171-180.

-5 Kanthala S, Gauthier T, Satyanarayanajois S: Structure-activity relationships of peptidomimetics that inhibit ppi of her2-her3. Biopolymers 2014;101:693-702.

6 Dittrich A, Gautrey H, Browell D, Tyson-Capper A: The her2 signaling network in breast cancer--like a spider in its web. J Mammary Gland Biol Neoplasia 2014;19:253-270.

$>7$ Lapin V, Shirdel EA, Wei X, Mason JM, Jurisica I, Mak TW: Kinome-wide screening of her2+ breast cancer cells for molecules that mediate cell proliferation or sensitize cells to trastuzumab therapy. Oncogenesis 2014;3:e133.

8 Huang L, Chen T, Chen C, Chen S, Liu Y, Wu J, Shao Z: Prognostic and predictive value of phospho-p44/42 and pakt in her2-positive locally advanced breast cancer patients treated with anthracycline-based neoadjuvant chemotherapy. World J Surg Oncol 2013;11:307.

-9 Rimawi MF, De Angelis C, Contreras A, Pareja F, Geyer FC, Burke KA, Herrera S, Wang T, Mayer IA, Forero A, Nanda R, Goetz MP, Chang JC, Krop IE, Wolff AC, Pavlick AC, Fuqua SAW, Gutierrez C, Hilsenbeck SG, Li MM, et al.: Low pten levels and pik3ca mutations predict resistance to neoadjuvant lapatinib and trastuzumab without chemotherapy in patients with her2 over-expressing breast cancer. Breast Cancer Res Treat 2018;167:731-740.

$>10$ Slamon DJ, Clark GM, Wong SG, Levin WJ, Ullrich A, McGuire WL: Human breast cancer: Correlation of relapse and survival with amplification of the her-2/neu oncogene. Science 1987;235:177-182.

$\checkmark 11$ Groheux D, Sanna A, Majdoub M, de Cremoux P, Giacchetti S, Teixeira L, Espie M, Merlet P, de Roquancourt A, Visvikis D, Hatt M, Resche-Rigon M, Hindie E: Baseline tumor 18f-fdg uptake and modifications after 2 cycles of neoadjuvant chemotherapy are prognostic of outcome in er+/her2- breast cancer. J Nucl Med 2015;56:824-831.

12 He L, Du Z, Xiong X, Ma H, Zhu Z, Gao H, Cao J, Li T, Li H, Yang K, Chen G, Richer JK, Gu H: Targeting androgen receptor in treating her2 positive breast cancer. Sci Rep 2017;7:14584.

13 Huang R, Han J, Liang X, Sun S, Jiang Y, Xia B, Niu M, Li D, Zhang J, Wang S, Wei W, Liu Q, Zheng W, Zhang G, Song Y, Panga D: Androgen receptor expression and bicalutamide antagonize androgen receptor inhibit beta-catenin transcription complex in estrogen receptor-negative breast cancer. Cell Physiol Biochem 2017;43:2212-2225.

14 Zheng FM, Long ZJ, Hou ZJ, Luo Y, Xu LZ, Xia JL, Lai XJ, Liu JW, Wang X, Kamran M, Yan M, Shao SJ, Lam EW, Wang SW, Lu G, Liu Q: A novel small molecule aurora kinase inhibitor attenuates breast tumor-initiating cells and overcomes drug resistance. Mol Cancer Ther 2014;13:1991-2003.

15 Lee HJ, Seo AN, Kim EJ, Jang MH, Kim YJ, Kim JH, Kim SW, Ryu HS, Park IA, Im SA, Gong G, Jung KH, Kim HJ, Park SY: Prognostic and predictive values of egfr overexpression and egfr copy number alteration in her2positive breast cancer. Br J Cancer 2015;112:103-111. 


\section{Cellular Physiology Cell Physiol Biochem 2018;50:52-65 \begin{tabular}{l|l|l} 
and Biochemistry Published online: 3 October 2018 & $\begin{array}{l}\text { ○ 2018 The Author(s). Published by S. Karger AG, Basel } \\
\text { www.karger.com/cpb }\end{array}$ \\
\hline
\end{tabular}}

Zhang et al.: Gab2 Ablation Reverses the Stemness Induced by HER2

-16 Hu N, Yin JF, Ji Z, Hong Y, Wu P, Bian B, Song Z, Li R, Liu Q, Wu F: Strengthening gastric cancer therapy by trastuzumab-conjugated nanoparticles with simultaneous encapsulation of anti-mir-21 and 5-fluorouridine. Cell Physiol Biochem 2017;44:2158-2173.

17 Giordano C, Catalano S, Panza S, Vizza D, Barone I, Bonofiglio D, Gelsomino L, Rizza P, Fuqua SA, Ando S: Farnesoid $\mathrm{x}$ receptor inhibits tamoxifen-resistant mcf-7 breast cancer cell growth through downregulation of her2 expression. Oncogene 2011;30:4129-4140.

18 D’Amato V, Raimondo L, Formisano L, Giuliano M, De Placido S, Rosa R, Bianco R: Mechanisms of lapatinib resistance in her2-driven breast cancer. Cancer Treat Rev 2015;41:877-883.

19 Rimawi MF, Schiff R, Osborne CK: Targeting her2 for the treatment of breast cancer. Annu Rev Med 2015;66:111-128.

20 Korkaya H, Wicha MS: Her2 and breast cancer stem cells: More than meets the eye. Cancer Res 2013;73:3489-3493.

-21 Korkaya H, Paulson A, Iovino F, Wicha MS: Her2 regulates the mammary stem/progenitor cell population driving tumorigenesis and invasion. Oncogene 2008;27:6120-6130.

22 Duru N, Fan M, Candas D, Menaa C, Liu HC, Nantajit D, Wen Y, Xiao K, Eldridge A, Chromy BA, Li S, Spitz DR, Lam KS, Wicha MS, Li JJ: Her2-associated radioresistance of breast cancer stem cells isolated from her2negative breast cancer cells. Clin Cancer Res 2012;18:6634-6647.

-23 Filipova A, Seifrtova M, Mokry J, Dvorak J, Rezacova M, Filip S, Diaz-Garcia D: Breast cancer and cancer stem cells: A mini-review. Tumori 2014;100:363-369.

24 Kong D, Li Y, Wang Z, Sarkar FH: Cancer stem cells and epithelial-to-mesenchymal transition (emt)phenotypic cells: Are they cousins or twins? Cancers (Basel) 2011;3:716-729.

25 Li J, Xu W, Yuan X, Chen H, Song H, Wang B, Han J: Polymer-lipid hybrid anti-her2 nanoparticles for targeted salinomycin delivery to her2-positive breast cancer stem cells and cancer cells. Int J Nanomedicine 2017;12:6909-6921.

-26 Gu H, Neel BG: The "gab" in signal transduction. Trends Cell Biol 2003;13:122-130.

-27 Wohrle FU, Daly RJ, Brummer T: Function, regulation and pathological roles of the gab/dos docking proteins. Cell Commun Signal 2009; 7:22.

28 Ding CB, Yu WN, Feng JH, Luo JM: Structure and function of gab2 and its role in cancer (review). Mol Med Rep 2015;12:4007-4014.

29 Daly RJ, Gu H, Parmar J, Malaney S, Lyons RJ, Kairouz R, Head DR, Henshall SM, Neel BG, Sutherland RL: The docking protein gab2 is overexpressed and estrogen regulated in human breast cancer. Oncogene 2002;21:5175-5181.

-30 Huang E, Cheng SH, Dressman H, Pittman J, Tsou MH, Horng CF, Bild A, Iversen ES, Liao M, Chen CM, West M, Nevins JR, Huang AT: Gene expression predictors of breast cancer outcomes. Lancet 2003;361:15901596.

-31 Fleuren ED, O’Toole S, Millar EK, McNeil C, Lopez-Knowles E, Boulghourjian A, Croucher DR, Schramek D, Brummer T, Penninger JM, Sutherland RL, Daly RJ: Overexpression of the oncogenic signal transducer gab2 occurs early in breast cancer development. Int J Cancer 2010;127:1486-1492.

-32 Bentires-Alj M, Gil SG, Chan R, Wang ZC, Wang Y, Imanaka N, Harris LN, Richardson A, Neel BG, Gu H: A role for the scaffolding adapter gab2 in breast cancer. Nat Med 2006;12:114-121.

-33 Wang Y, Sheng Q, Spillman MA, Behbakht K, Gu H: Gab2 regulates the migratory behaviors and e-cadherin expression via activation of the pi3k pathway in ovarian cancer cells. Oncogene 2012;31:2512-2520.

-34 Cheng J, Zhong Y, Chen S, Sun Y, Huang L, Kang Y, Chen B, Chen G, Wang F, Tian Y, Liu W, Feng GS, Lu Z: Gab2 mediates hepatocellular carcinogenesis by integrating multiple signaling pathways. FASEB J 2017;31:55305542.

-35 Chen Y, Liu Q, Wu M, Li M, Ding H, Shan X, Liu J, Tao T, Ni R, Chen X: Gab2 promotes cell proliferation by activating the erk signaling pathway in hepatocellular carcinoma. Tumour Biol 2016;37:11763-11773.

-36 Horst B, Gruvberger-Saal SK, Hopkins BD, Bordone L, Yang Y, Chernoff KA, Uzoma I, Schwipper V, Liebau J, Nowak NJ, Brunner G, Owens D, Rimm DL, Parsons R, Celebi JT: Gab2-mediated signaling promotes melanoma metastasis. Am J Pathol 2009;174:1524-1533.

37 Brummer T, Schramek D, Hayes VM, Bennett HL, Caldon CE, Musgrove EA, Daly RJ: Increased proliferation and altered growth factor dependence of human mammary epithelial cells overexpressing the gab2 docking protein. J Biol Chem 2006;281:626-637.

-38 Yuan Y, Qin L, Liu D, Wu RC, Mussi P, Zhou S, Songyang Z, Xu J: Genetic screening reveals an essential role of p27kip1 in restriction of breast cancer progression. Cancer Res 2007;67:8032-8042. 


\section{Cellular Physiology Cell Physiol Biochem 2018;50:52-65 \begin{tabular}{l|l|l|l} 
DOI: 10.1159/000493957 2018 The Author(s). Published by S. Karger AG, Basel \\
\hline
\end{tabular} and Biochemistry}

Zhang et al.: Gab2 Ablation Reverses the Stemness Induced by HER2

-39 Shi L, Sun X, Zhang J, Zhao C, Li H, Liu Z, Fang C, Wang X, Zhao C, Zhang X, Zhou F, Lu S, Luo R, Zhang B: Gab2 expression in glioma and its implications for tumor invasion. Acta Oncol 2013;52:1739-1750.

40 Bocanegra M, Bergamaschi A, Kim YH, Miller MA, Rajput AB, Kao J, Langerod A, Han W, Noh DY, Jeffrey SS, Huntsman DG, Borresen-Dale AL, Pollack JR: Focal amplification and oncogene dependency of gab2 in breast cancer. Oncogene 2010;29:774-779.

-41 Ke Y, Wu D, Princen F, Nguyen T, Pang Y, Lesperance J, Muller WJ, Oshima RG, Feng GS: Role of gab2 in mammary tumorigenesis and metastasis. Oncogene 2007;26:4951-4960.

42 Adams SJ, Aydin IT, Celebi JT: Gab2--a scaffolding protein in cancer. Mol Cancer Res 2012;10:1265-1270.

-43 Yang Y, Wu J, Demir A, Castillo-Martin M, Melamed RD, Zhang G, Fukunaga-Kanabis M, Perez-Lorenzo R, Zheng B, Silvers DN, Brunner G, Wang S, Rabadan R, Cordon-Cardo C, Celebi JT: Gab2 induces tumor angiogenesis in nras-driven melanoma. Oncogene 2013;32:3627-3637.

44 Wang WJ, Mou K, Wu XF, Zhang JZ, Ren G, Qi JD, Xu YF, Yao X: Grb2-associated binder 2 silencing impairs growth and migration of h1975 cells via modulation of pi3k-akt signaling. Int J Clin Exp Pathol 2015;8:10575-10584.

45 Al-Hajj M, Wicha MS, Benito-Hernandez A, Morrison SJ, Clarke MF: Prospective identification of tumorigenic breast cancer cells. Proc Natl Acad Sci U S A 2003;100:3983-3988.

-46 O’Brien CA, Pollett A, Gallinger S, Dick JE: A human colon cancer cell capable of initiating tumour growth in immunodeficient mice. Nature 2007;445:106-110.

-47 Boiko AD, Razorenova OV, van de Rijn M, Swetter SM, Johnson DL, Ly DP, Butler PD, Yang GP, Joshua B, Kaplan MJ, Longaker MT, Weissman IL: Human melanoma-initiating cells express neural crest nerve growth factor receptor cd271. Nature 2010;466:133-137.

48 Nair R, Roden DL, Teo WS, McFarland A, Junankar S, Ye S, Nguyen A, Yang J, Nikolic I, Hui M, Morey A, Shah J, Pfefferle AD, Usary J, Selinger C, Baker LA, Armstrong N, Cowley MJ, Naylor MJ, Ormandy CJ, et al.: $\mathrm{C}$-myc and her2 cooperate to drive a stem-like phenotype with poor prognosis in breast cancer. Oncogene 2014;33:3992-4002.

49 Louie E, Nik S, Chen JS, Schmidt M, Song B, Pacson C, Chen XF, Park S, Ju J, Chen EI: Identification of a stemlike cell population by exposing metastatic breast cancer cell lines to repetitive cycles of hypoxia and reoxygenation. Breast Cancer Res 2010;12:R94.

\$50 Marotta LL, Almendro V, Marusyk A, Shipitsin M, Schemme J, Walker SR, Bloushtain-Qimron N, Kim JJ, Choudhury SA, Maruyama R, Wu Z, Gonen M, Mulvey LA, Bessarabova MO, Huh SJ, Silver SJ, Kim SY, Park SY, Lee HE, et al.: The jak2/stat3 signaling pathway is required for growth of cd44(+)cd24(-) stem cell-like breast cancer cells in human tumors. J Clin Invest 2011;121:2723-2735.

-51 Farnie G, Clarke RB, Spence K, Pinnock N, Brennan K, Anderson NG, Bundred NJ: Novel cell culture technique for primary ductal carcinoma in situ: Role of notch and epidermal growth factor receptor signaling pathways. J Natl Cancer Inst 2007;99:616-627.

52 Li X, Lewis MT, Huang J, Gutierrez C, Osborne CK, Wu MF, Hilsenbeck SG, Pavlick A, Zhang X, Chamness GC, Wong H, Rosen J, Chang JC: Intrinsic resistance of tumorigenic breast cancer cells to chemotherapy. J Natl Cancer Inst 2008;100:672-679.

-53 Korkaya H, Paulson A, Charafe-Jauffret E, Ginestier C, Brown M, Dutcher J, Clouthier SG, Wicha MS: Regulation of mammary stem/progenitor cells by pten/akt/beta-catenin signaling. PLoS Biol 2009;7:e1000121.

54 Xu C, Sun X, Qin S, Wang H, Zheng Z, Xu S, Luo G, Liu P, Liu J, Du N, Zhang Y, Liu D, Ren H: Let-7a regulates mammosphere formation capacity through ras/nf-kappab and ras/mapk/erk pathway in breast cancer stem cells. Cell Cycle 2015;14:1686-1697.

55 Han D, Wu G, Chang C, Zhu F, Xiao Y, Li Q Zhang T, Zhang L: Disulfiram inhibits tgf-beta-induced epithelialmesenchymal transition and stem-like features in breast cancer via erk/nf-kappab/snail pathway. Oncotarget 2015;6:40907-40919.

56 Ginestier C, Liu S, Diebel ME, Korkaya H, Luo M, Brown M, Wicinski J, Cabaud O, Charafe-Jauffret E, Birnbaum D, Guan JL, Dontu G, Wicha MS: Cxcr1 blockade selectively targets human breast cancer stem cells in vitro and in xenografts. J Clin Invest 2010;120:485-497. 